\title{
A Regional Short-Run Forecasting Model Of Coal Demand By Electric Utilities
}

\author{
Noel D. Uri*
}

\section{INTRODUCTION}

For the foreseeable future, it is unlikely that any factor will be of greater importance to the economic planning of a particular region than the availability of energy in general and electrical energy in particular. To facilitate this planning, accurate forecasts of, among other things, electrical energy demand are needed. Much research has been done on the longer-run aspects of demand. ${ }^{1}$ It has generally been the case that a structural econometric model performs admirably in forecasting aggregate annual kilowatt-hour demand. In the short-run at a regionally disaggregated level, however, the results have not been as satisfactory. The unreliability and unavailability of the data, the strong influence of the weather, and the structurally changing characteristics of demand all combine to produce a generally unacceptable forecasting model. Further, since the consumption of coal is inexorably intertwined with generation (electric utilities consumed 75 percent of all coal mined in 1976), poor short-run forecasts of generation naturally lead to poor forecasts of coal consumption.

Realizing the foregoing problems exist, this paper develops a short-run forecasting model for electrical energy generation and coal consumption by electric utilities that overcomes them and, at least over the test period, has provided excellent regional forecast results.

\section{AN ANNUAL MODEL OF ELECTRIC UTILITY CONSUMPTION OF COAL}

The demand for coal by electric utilities is dependent on the demand for electrical energy, coal-fired generating capacity, and the relative costs of generating electrical energy using alternative boiler fuels. An increase in the demand for electrical energy will result in an increase in the demand for factors of production providing they are not undesirable for some specific reason. Thus, as the demand for electrical energy increases, for

*The author is an economist with the Department of Energy. The views expressed are those of the author and do not necessarily represent the policies of the Department of Energy or the views of other Department of Energy staff members. 
whatever reason, the demand for coal used to generate electrical energy would also be expected to increase.

\section{a. Contingencies}

There exist many factors affecting the decision environment of electric utilities in their choice of fuel mix and operating options that cannot be easily quantified. Some examples include:

- The Clean Air Act resulted in air quality standards that forced, at least in the short-run, a shift away from high sulfur coal to low sulfur coal and oil and natural gas. Consequently, the demand for coal became dependent on factors other than heat content and price. Coal prices have begun to reflect premiums for more preferable types of coal, based upon sulfur, ash, water, and other chemical contents.

- The cost of natural gas in recent years has been regulated below the market equilibrium price and consequently has been allocated to users based on Federal Energy Regulatory Commission priorities. As a result, the observed market price of natural gas does not reflect the economic incentive of electric utilities which currently exists to substitute other fuels for natural gas.

- The consumption of coal is limited by the eapacity of coal burning equipment. Given the long lead time between an investment decision and operation of a combustor, attempts to forecast changes in fuel generating capacity in response to relevant economic factors through an econometric model is not possible.

- The Arab oil embargo and the accompanying energy crisis altered many of the structural relationships previously existing. For example, the trend toward increased oil consumption on the East Coast has been altered. Coal is gaining in importance.

\section{b. Methodology}

Because of the inherent limitations alluded to above, a hybrid approach has been adopted to provide a forecast of the demand for coal by electric utilities.

Total annual generation of electrical energy in a given region can be correctly viewed as the electrical energy generated for consumption by residential, commercial, and industrial users, both within the region and outside of the region. In general, the demand for electrical energy by commercial and industrial consumers is a derived demand based on the demand for the goods and services they provide. Similarly, the demand for electrical energy by residential consumers is a derived demand based on the demand for the output of the stock of energy using capital goods (e.g., heaters, ranges, and so on). As such, when specifying a relationship it is common practice to include electrical generation as a lagged endogenous term (see Uri [14] for the theoretical justification). 
These considerations suggest the following functional specification for electrical energy generation:

(1) $\mathrm{ET}_{\mathrm{t}}=\mathrm{f}\left(\mathrm{ET}_{\mathrm{t}-1}, \mathrm{ECON}_{\mathrm{t}}\right)$

where ET is total electrical energy generation in a particular region; ECON is a vector of the relevant economic variables affecting generation (e.g., price, income); and

$\mathrm{t}$ denotes the period (annual).

Note that this approach necessarily subsumes many of the structural realities existing in each region. The estimated relationships reflect the compounding of many structural parameters.

Preliminary statistical analyses and availability of forecasts of the exogenous variables were used to select the economic variables to include as well as the exact functional form adopted.

The model which proved to be most accurate among those considered has the following form:

(la) $\log \mathrm{ET}_{\mathrm{t}}=\mathrm{a}_{0}+\mathrm{a}_{1} \log \mathrm{ET}_{\mathrm{t}-1}+\mathrm{a}_{2} \log \mathrm{EA}_{\mathrm{t}}+$

$$
\mathrm{a}_{3} \log \mathrm{P}_{\mathrm{t}}+\epsilon_{\mathrm{t}}
$$

where $\mathrm{EA}_{\mathrm{t}}$ is a national indicator of economic activity (personal disposable income or industrial production depending on whether the major component of generation in a specific region came from residential/commercial consumers or industrial consumers);

$P_{t}$ denotes the real weighed average price of electrical energy to all consumers; ${ }^{3}$

$\mathrm{a}_{0}, \mathrm{a}_{1}, \ldots, \mathrm{a}_{3}$ are parameters to be estimated;

$\epsilon$ is the error term; and

log denotes the natural logarithm (to the base e) transformation.

The other variables are as previously defined.

In this generation model no provision is made for substitution of other energy sources in response to relative price changes. Preliminary results did not show the price of other fuels (coal, oil, and natural gas) to be statistically significant. Other variables such as the price of electric appliances and machinery were similarly insignificant.

There are two notable observations about the adopted form: the first is 
the use of national economic activity indicators and the second is the use of average rather than marginal prices. National indicators of economic activity were used in deference to regional measures because of the measurement problem inherent in such disaggregated measures as well as the fact that forecasts of national indicators are generally available. Average prices were used because marginal prices across consumer classes do not exist. Even if they did, it would be impossible to determine which block of the declining block rate schedule should be used.

The second component of the demand for coal by electric utilities involves a relationship between the coal consumed by utilities and generation and the price of competing boiler fuels.

The economic argument indicated that the following form be adopted:

(2) $\mathrm{C}_{\mathrm{t}}=\mathrm{g}\left(\mathrm{ET}_{\mathrm{t}}, \mathrm{FP}_{\mathrm{t}}, \mathrm{DU} \mathrm{M}_{\mathrm{t}}\right)$

where $\mathrm{C}$ is the coal consumed for generation by electric utilities;

FP represents a vector of the prices of fuels used for generation;

DUM is a qualitative variable included to account for sulfur emission controls beginning in 1969; and

$\mathrm{ET}$ is generation.

As in the case of generation, the specific functional form selected is based on a goodness-of-fit test. This proved to be:

(2a) $\log \mathrm{C}_{\mathrm{t}}=\mathrm{b}_{\mathrm{o}}+\mathrm{b}_{1} \log \mathrm{ET}_{\mathrm{t}}+\mathrm{b}_{2} \mathrm{PC}_{\mathrm{t}}+\mathrm{b}_{3} \mathrm{PO}_{\mathrm{t}}+$

$$
\mathrm{b}_{4} \mathrm{PG}_{\mathrm{t}}+\mathrm{b}_{5} \mathrm{DUM}_{\mathrm{t}}+\eta_{\mathrm{t}}
$$

where PC, PO, and PG denote the delivered price of coal, oil, and natural gas to electric utilities, respectively (transformed by $\log$ to the base e);

$b_{0}, b_{1}, \ldots, b_{5}$ are parameters to be estimated; and

$\eta$ is the error term.

The other variables are as previously defined.

The two foregoing equations allow for the forecast of the total demand for coal and total generation by electric utilities on an annual and regional basis. Attempts to estimate the model on the basis of shorter time intervals (i.e., quarterly and monthly) met with failur in the sense that the estimated results were not believable and not robust even when appropriate seasonal factors (e.g., weather variation) were taken into account. The results at the regional level on an annual basis were satisfactory and consistent with other work. It is to these results, we now turn. 


\section{c. Estimation of the Model}

In using the model to forecast, estimates of the parameters (i.e., $a_{0}, a_{1}$, $\left.\ldots, a_{3} ; b_{0}, b_{1}, \ldots, b_{5}\right)$ are needed. Since the model involves two simultaneous equations (equations (1a) and (2a)), two stage least squares was used to estimate these parameters.

The coal consumption and generation data were obtained from Federal Energy Regulatory Commission (FERC) Form 4, the fuel price data were obtained from FERC Form 423 , the price of electrical energy data were obtained from FERC Form 1 , and the economic activity data were obtained from the Bureau of Economic Analysis. The data were deflated to constant 1967 dollars. The model was estimated on an annual basis for the New England Region, ${ }^{4}$ New York and a region consisting of Pennsylvania, New Jersey and Maryland and Delaware (PJM). In the actual estimation state data covering the period 1965 through 1976 were pooled regionally with the use of a dummy variable for each state. ${ }^{5}$

While the regional definitions adopted (except for New England) do not conform to any of the usual classifications (e.g., Census, Bureau of Economic Analysis, etc.), they do follow an institutional structure. The electric utilities in New York are combined into a formal power pool where all five utilities in the state generate electrical energy on the basis of a least cost criterion. A similar arrangement exists between most utilities operating in Pennsylvania, New Jersey and Maryland and Delaware.

A priori, for equation (la), one would expect the coefficient on economic activity to be positive indicating that an increase in it will increase the demand for electrical energy and, hence, generation. The coefficient on price should be negative suggesting that an increase in price will result in a decrease in the quantity of electrical energy demanded. For equation(2a), the expectations are that the coefficient on generation should be positive since additional generation necessarily leads to additional coal consumption, the coefficient on the price of coal should be negative whereas the coefficients on the price of oil and natural gas should be positive. This pattern of the signs of the coefficients evolves since in the multifuel environment of electrical energy generation utilities have the technological flexibility to substitute one fuel for another (Uri [12]).

The empirical results which are presented in Table 1 indicate that the model specification fits the data well. ${ }^{6}$ For the generation equation, it is not surprising that the lagged term is the most significant factor explaining generation in the current period. Consumer response to price changes is significant as is response to economic activity changes. If one gives the price coefficient an elasticity interpretation, for example, a one percent increase in the price will result in a 0.10 percent decrease in generation in New England, a 0.22 percent decrease in generation in New York, and a 0.12 percent decrease in the PJM Region. The adjustment of consumers to changes in the exogenous factors as indicated by the coefficient on the lagged term is relatively quick. Thus, the rapid adjustment by consumers results in a long-run price elasticity of $-1.37,-0.82$, and -1.12 for the New England, New York, and PJM regions, respectively. This is within the 
range of what is generally agreed upon to be the true price elasticity (Taylor $[10]$ ).

In the equations of electric utility demand for coal generation, as previously suspected, is the most significant factor. Further, the results indicate that utilities are truly responding to the relative change in the price of coal. That is, less coal is being used as the price of it increases. Oil is one fuel being substituted for coal but natural gas is not. The fact that the price of natural gas is not significant undoubtedly lies in the fact that natural gas curtailments to utilities became a significant consideration in

\section{TABLE 1}

Coefficient Estimates for Equations (1a) and $(2 \mathrm{a})^{(1,2)}$

\begin{tabular}{cccc}
\hline Coefficient & New England & New York & PJM \\
$1, \mathrm{a}_{\mathrm{o}}$ & 1.189 & 8.049 & 6.133 \\
& $(0.807)$ & $(2.252)$ & $(3.539)$ \\
2. $\mathrm{a}_{1}$ & 0.925 & 0.733 & 0.892 \\
& $(0.050)$ & $(0.207)$ & $(0.231)$ \\
3. $\mathrm{a}_{2}{ }^{(3)}$ & 0.147 & 0.258 & 0.140 \\
& $(0.068)$ & $(0.089)$ & $(0.069)$ \\
4. $\mathrm{a}_{3}$ & -0.103 & -0.218 & -0.121 \\
& $(0.009)$ & $(0.106)$ & $(0.053)$ \\
$\mathrm{R}^{2}$ & 0.961 & 0.932 & 0.965 \\
$5 . \mathrm{b}_{0}$ & 3.832 & -1.225 & 2.758 \\
& $(4.579)$ & $(4.437)$ & $(0.649)$ \\
$6 . \mathrm{b}_{1}$ & 0.543 & 1.029 & 0.724 \\
& $(0.248)$ & $(0.264)$ & $(0.301)$ \\
$7 . \mathrm{b}_{2}$ & -0.985 & -1.0617 & -0.926 \\
& $(0.452)$ & $(0.5009)$ & $(0.268)$ \\
$8 . \mathrm{b}_{3}$ & 0.386 & 0.891 & 0.451 \\
& $(0.124)$ & $(0.355)$ & $(0.199)$ \\
$9 . \mathrm{b}_{4}$ & 0.256 & 0.521 & 0.419 \\
& $(0.262)$ & $(0.673)$ & $(0.577)$ \\
$10 . \mathrm{b}_{5}$ & -0.1551 & -0.0907 & -0.113 \\
$\mathrm{R}^{2}$ & $(0.0549)$ & $(0.0368)$ & $(0.0463)$ \\
$\mathrm{D}^{2} \mathrm{~W}^{(4)}$ & 0.926 & 0.899 & 0.877 \\
\hline & 1.575 & 1.666 & 2.080 \\
\hline
\end{tabular}

'Standard errors of estimates in parentheses.

${ }^{2}$ Estimates of the state intercepts are not reported. They are available from the author upon request.

${ }^{3}$ Industrial production was used as the measure of economic activity for New England and personal income was the measure used for the other regions.

${ }^{4}$ Durbin-Watson statistic. 
1970 and after (although the percentage of natural gas used by electric utilities in the two regions to fire conventional boilers did not measurably decline until 1973). The unavailability of natural gas did not make it a viable substitute fuel over much of the estimation period. The coefficient on the dummy variable included to account for sulfur emissions controls indicates a distinct non-price induced shift away from using coal.

These results then, represent the vehicle around which regional electrical energy generation and regional coal consumption by electric utilities are forecast. What is desired, however, are forecasts of these variables on a monthly basis. The decomposition of the annual forecasts is the subject of the next section.

\section{A MONTHLY MODEL OF ELECTRIC UTILITY COAL CONSUMPTION}

\section{a. Methodology}

The key to forecasting the monthly level of generation which is used to forecast electric utility coal consumption rests on forecasting the normalized monthly generation in kilowatt-hours. Initially, normalized monthly loads were constructed from hourly load data for Federal Energy Regulatory Commission (FERC) Region 1 which corresponds to the New England Region and FERC Region 2 which corresponds approximately to a combined New York and PJM Region. Monthly and annual load duration curves were constructed from these data. ${ }^{7}$ Integration under these curves yielded monthly and annual generation. The normalized monthly generation was then computed by dividing monthly generation by total annual generation of the year in which the monthly generation occurred. Consequently, the sum of normalized monthly generation over a year equals one.

The normalized monthly generation data $Z_{t}$, were fit to a Box-Jenkins model of the general form,

(3) $\phi \mathrm{p}(\mathrm{B}) \nabla^{\mathrm{d}} \mathrm{Z}_{\mathrm{t}}=\theta \mathrm{q}(\mathrm{B}) \mathrm{q}_{\mathrm{t}}$

where $\mathrm{B}$ is the backward shift generator $\mathrm{BZ} \mathrm{Z}_{\mathrm{t}}=\mathrm{Z}_{\mathrm{t}-1}$; and in general,

(4) $\mathrm{B}^{\mathrm{m}} \mathrm{Z}_{\mathrm{t}}=\mathrm{Z}_{\mathrm{t}-\mathrm{m}}$;

where $\phi p(B)$ and $\theta q(B)$ are polynomials in $B$ of order $p$ and $q$, respectively, satisfying the stationarity and invertability conditions ${ }^{8}$ so that

(5) $\phi \mathrm{p}(\mathrm{B})=1-\phi_{1} \mathrm{~B}-\phi_{2} \mathrm{~B}^{2}-\ldots-\phi \mathrm{pB}^{\mathrm{p}}$ (autoregressive component)

(6) $\theta \mathrm{q}(\mathrm{B})=1-\theta_{1} \mathrm{~B}-\theta_{2} \mathrm{~B}^{2}-\ldots-\theta \mathrm{qB}^{4}$ (moving average component)

(7) $\nabla Z_{t}=Z_{t}-Z_{t-1}$

where $\mathrm{d}$ is the order of the difference operator, and 
$a_{t}$ is a white noise (error) series that is assumed to be normally distributed with mean zero and some finite variance.

\section{b. Empirical Results}

Beyond specifying the general functional form of the Box-Jenkins model there are three distinct steps in implementing the approach: identification, estimation, and forecasting.

The first stage in applying the Box-Jenkins method is identification. To this end, the sample autocorrelation functions of the series of normalized monthly generation for the New England Region and the combined New York/PGM Region were computed. (These are available from the author.)

The objective in studying the sample autocorrelations is to recognize in them a pattern typical of an ARIMA (integrated autoregressive-movingaverage) process with which one is familiar such as a first-order autoregressive process which declines approximately, though not precisely, in exponential fashion. A great deal of the skill required to apply the BoxJenkins technique involves the ability to look at an estimate of the autocorrelation function and determine which ARIMA model might be associated with it.

The existence of a significant autocorrelation at a lag of 12 indicated a twelve-period seasonal component. Further, the autocorrelations have an appearance suggesting a twelfth order moving average type model (with an additional first order moving average term). Thus, the simple model

(3a) $\left(1-\mathrm{B}^{12}\right) \mathrm{Z}_{\mathrm{t}}=\left(1-\theta_{1} \mathrm{~B}-\theta_{12} \mathrm{~B}^{12}\right) \mathrm{a}_{\mathrm{t}}$

where $Z_{t}$ are the normalized monthly generation estimates; and

$\mathrm{a}_{\mathrm{t}}$ are independent random deviates with mean zero and variance $\sigma_{\mathrm{a}}{ }^{2}$ was tentatively entertained to represent the series.

The parameters were estimated and can be found in Table 2. The autocorrelations of the residuals $\hat{a}_{t}$ exhibit no systematic pattern in either region. The average of the residuals is 1.8038 and 3.1704 and the estimated standard errors are 3.0472 and 6.9437 for the New England and the combined New York and PJM Region, respectively, strongly suggesting that the $a_{t}$ have zero means. Consequently, (3a) is taken to be the appropriate model for the series $Z_{t}$ in both regions.

Being more refined on this, suppose it is assumed that the $a_{t}$ are independent and normally distributed with mean zero and variance $\sigma_{\mathrm{a}}{ }^{2}$. It can then be shown for large samples that the autocorrelations of $\hat{a}_{t}$ will be independent and normally distributed with mean zero and variance approximately $1 / \sqrt{\mathrm{T}}$ where $\mathrm{T}$ is the number of observations (Nelson $[7$, p. 6]). In the present instance, none of 48 computed autocorrelations were significantly different from zero at the 0.95 level for any region.

With the model identified and estimated, the final step in using the 
TABLE 2

Box-Jenkins Parameter Estimates for Equation (3a)

95 Percent Confidence Interval

Parameter Estimate Lower Limit Upper Limit

a. New England

$\begin{array}{llll}\theta_{1} & 0.6568 & 0.4914 & 0.8222 \\ \theta_{12} & 0.4238 & 0.2164 & 0.6311\end{array}$

b. New York/PJM

$\begin{array}{llll}\theta_{1} & 0.1663 & 0.0417 & 0.3744 \\ \theta_{12} & 0.7759 & 0.6540 & 0.8950\end{array}$

107 degrees of freedom.

Box-Jenkins technique is to forecast with it. A discussion of how the forecasting is carried out can be found in (Thompson and Tiao [11, pp. 529-531]).

What results from the forecasts are monthly proportions of total annual generation. These proportions can then be used to temporally disaggregate the annual generation and coal consumption forecasts resulting from the econometric approach. Because data do not exist to permit forecasting normalized monthly generation for New York and PJM regions separately, the single series normalized forecasts for FERC Region 2 were applied to both of the regions.

The forecast results based on the fitted model were extremely good. For example the normalized monthly loads for a year should sum to one. In the worst instance, the sum was equal to one to the fifth decimal place. Additionally, confidence intervals based on a 95 percent level with an underlying assumption of normality are very small indicating the model specification performs well.

The confidence intervals were based on the confidence intervals computed from the Box-Jenkins forecasts. They are at the 95 percent level with an underlying assumption of normality. As can be seen from the results, these intervals are very small, i.e., the model specification performs well.

This approach to forecasting monthly regional generation has a weakness in that it completely abstracts from any weather sensitivity. While weather is, on the average, not an important variable in an annual model ${ }^{9}$ it is the most important variable in explaining month to month departures from normal. The analysis of the impact of weather, therefore, is the subject of the next section.

\section{A MODEL OF WEATHER SENSITIVITY ${ }^{10}$}

\section{a. Methodology}

Since the concern is with the importance of weather to the exclusion of 
all else, a model of weather sensitivity is structured in such a fashion that all other components of the set of factors affecting demand are relegated to subsidiary positions.

Consider normalized monthly generation as previously defined for a given region over a finite horizon. To the extent that prices, economic activity, capital stock, and consumer characteristics are constant or change very slowly and regularly from one month to the next, the only factor appreciably affecting normalized monthly generation will be the weather. ${ }^{11}$

This being the case, it is important to define measures of weather. Several weather variables including monthly average heating degree days, ${ }^{12}$ average cooling degree days, monthly average temperature, and wind speed are generally available by region from the National Oceanic and Atmospheric Administration. Preliminary analyses showed the degree day measures to be the best explanatory variables. Thus, the model is specified as,

(8) $\mathrm{Z}_{\mathrm{t}}=\alpha_{\mathrm{o}}+\alpha_{1} \mathrm{X}_{1 \mathrm{t}}+\alpha_{2} \mathrm{X}_{2 \mathrm{t}}+\xi_{\mathrm{t}}$

where $\mathrm{Z}$ denotes the normalized monthly generation;

$\mathrm{X}_{1}$ denotes the monthly heating degree days;

$\mathrm{X}_{2}$ denotes the monthly cooling degree days;

$\mathrm{t}$ denotes the period (monthly);

$\xi$ is the error term; and

$\alpha_{0}, \alpha_{1}$, and $\alpha_{2}$ denote parameters to be estimated.

This particular functional form was selected on the basis of a simple goodness-of-fit test. Other specifications were considered (e.g., semilogarithmic, logarithmic, and hyperbolic) but all proved to be inferior to the one selected.

In defining a measure of weather sensitivity, the one that most quickly comes to mind is elasticity which allows one to determine the percentage effect on normalized generation of, say, a one percent increase in the number of heating degree days. Formally defined for heating degree days, it is

(9) $\frac{\partial \mathrm{Z}_{\mathrm{t}}}{\partial \mathrm{X}_{1 \mathrm{t}}} \cdot \frac{\mathrm{X}^{*} \mathrm{Z}^{*}}{\mathrm{Z}^{*}}=\alpha_{1} \cdot \frac{\mathrm{X}^{*}}{\mathrm{Z}^{*}}$

where $X^{*}{ }_{1}$ and $\mathrm{Z}^{*}$ denote the average values of the variables

$\mathrm{X}_{1}$ and $\mathrm{Z}$ over some period.

Thus, for example, if it is desired to compute the January heating degree day elasticity over a period of three years, then $\mathrm{X}^{*}{ }_{1}$ represents an arithmetic mean of the heating degree days in January for the three years of interest while $\mathrm{Z}^{*}$ is the mean of the January proportions. 
The cooling degree day elasticity is analogously defined.

Be cautious to observe that what this elasticity is measuring is not the absolute change in monthly generation due to a change in weather but rather the change in monthly generation relative to total annual generation due to a change in weather. Therefore, a one percent increase in January heating degree days, say, might result in a 0.2 percent increase in normalized January generation. In computing the magnitude of the expansion of generation, total annual generation is the base to which this factor is applied and not total monthly generation.

\section{b. Data}

Before presenting the estimation results of equation (8) and estimates of the elasticities, a discussion of the weather data is in order.

Monthly heating degree day and cooling degree day data were obtained from the National Oceanic and Atmospheric Administration on a state basis. Regional monthly data were then computed by weighing each state's contribution to the measure by its proportion of total annual generation in the region.

Note that a total of 120 observations on the weather variables is used in estimation.

The model is estimated for FERC Region 1 and FERC Region 2.

\section{Estimation Results}

The first step in obtaining measures of weather sensitivity of generation is the estimation of equation (8). A priori, the exclusion of economic, capital stock and socio-demographic variables would be expected to introduce a marked degree of serial correlation. Such, however, did not prove to be the situation. The two weather variables fit the data exceptionally well $\left(\mathrm{R}^{2} \mathrm{~s}\right.$ were 0.85 and 0.86 for the two regions). Additionally, the absence of serial correlation was indicated for each region by the Durbin-Watson statistic. The implication of this is the following:

It is well known that most economic variables tend to be serially correlated (Ames and Reiter [1]). If a significant serially correlated variable has been excluded from the set of explanatory variables, obviously its influence will be reflected in the random variable, $\xi$. Since this serial correlation is absent in the current estimates one is safe in concluding that the failure to include, say, prices is not particularly damaging to the statistical properties of the estimates of the coefficients $\alpha_{1}$ and $\alpha_{2}$ in equation (8). The estimates were obtained by ordinarily least squares and are presented in Table 3.

The actual measures of weather sensitivity, the heating degree day and cooling degree day elasticities, were computed based on equation (9). Because the desire is for monthly elasticities (e.g., a heating degree day elasticity for January), the average number of heating degree days, number of cooling degree days, and normalized monthly loads for each month over the period 1965 through 1974 were used. The results are presented in Table 4 and Table 5 . The credibility of these results is dis- 
TABLE 3

Estimation Results for Equation $(8)^{1}$

\begin{tabular}{ccc}
\hline \multirow{2}{*}{ Coefficient } & \multicolumn{2}{c}{ Region } \\
1. $\alpha_{0}$ & 0.076080 & New York/PGM \\
2. $\alpha_{1}$ & $(0.000809)$ & 0.077641 \\
& $(0.000008)$ & $0.0000710)$ \\
3. $\alpha_{2}$ & $(0.000001)$ & $(0.000001)$ \\
R & $(0.000056)$ & $(0.000032)$ \\
D.W. & $(0.000004)$ & $(0.000005)$ \\
\hline
\end{tabular}

${ }^{1}$ Standard errors of estimates in parentheses.

cussed in the previously mentioned paper. Note that, as before, the estimates for FERC Region 2 are used for both New York and the PJM Region.

In the forecasting problem, these elasticity estimates are used to assess the impact of an expected warmer than normal summer or a colder than normal winter. Thus, for example, if the question is asked what would be the effect on generation of a ten percent warmer July in New England (i.e., ten percent more cooling degree days), the response is that it would increase total annual generation in New England by 1.5 percent.

A combination of the foregoing models provides a methodology with which to forecast monthly generation for the New England Region, New York, and the Pennsylvania, New Jersey, and Maryland Region. It is to these forecasts we now turn.

Before doing so, however, it is instructive to recapitulate the mechanics of disaggregating the annual forecasts:

(1) After obtaining the annual forecasts via the relations (1a) and (2a), they are decomposed into monthly forecasts from the Box-Jenkins forecasts of normalized monthly generation. Note that this precludes the necessity of forecasting monthly values of prices, economic activity, etc.

(2) Upon obtaining monthly forecasts of generation and coal consumption by electric utilities, possible variations in the weather can be analyzed. Specifically, monthly changes in generation (either increases or decreases) can be computed based upon the degree day elasticity estimates and hypothesized (or realized in the case of checking the accuracy of the model) percentage changes in the degree days. These values are then added to the monthly forecasts obtained in the preceding step.

\section{FORECASTING MONTHLY GENERATION AND COAL CONSUMPTION BY ELEGTRIC UTILITIES}

Before proceeding to forecast the monthly generation and coal con- 
TABLE 4

Normalized Heating Degree Day Elasticities

\begin{tabular}{ccccccccccccc}
\hline Region & Jan. & Feb. & March & April & May & June & July & Aug. & Sept. & Oct. & Nov. & Dec. \\
New England & 0.1091 & 0.1057 & 0.0824 & 0.0527 & 0.0252 & 0.0033 & 0.0005 & 0.0010 & 0.0093 & 0.0360 & 0.0665 & 0.0890 \\
New York/PJM & 0.1015 & 0.0964 & 0.0724 & 0.0414 & 0.0203 & 0.0034 & 0.0006 & 0.0012 & 0.0081 & 0.0315 & 0.0623 & 0.0832 \\
\hline
\end{tabular}

TABLE 5

Normalized Cooling Degree Day Elasticities

\begin{tabular}{ccccccccccccc}
\hline & & & & & & & & & & & \\
Region & Jan. & Feb. & March & April & May & June & July & Aug. & Sept. & Oct. & Nov. & Dec. \\
New England & 0.0 & 0.0 & 0.0001 & 0.0001 & 0.0158 & 0.0812 & 0.1545 & 0.1341 & 0.0589 & 0.0032 & 0.0 & 0.0 \\
New York/PJM & 0.0000 & 0.0 & 0.0013 & 0.0011 & 0.0194 & 0.0627 & 0.0919 & 0.0751 & 0.0356 & 0.0042 & 0.0 & 0.0 \\
\hline
\end{tabular}


sumption by electric utilities a caveat needs to be inserted. The forecasts presented represent estimates of short-run generation and coal consumption developments. They are extensions of recent historical patterns and, as such, do not reflect the potential impact of policy initiatives such as the coal conversion segments of the National Energy Plan on future coal consumption.

The time horizon selected for the forecasts is three years. To give an indication of how well the model performs, the forecasts of monthly 1977 generation and electric utility coal consumption for New England, New York, and the PJM Region are compared with actual 1977 generation and coal consumption. Quarterly forecasts of these values for 1978 and an annual forecast for 1979 for the three regions are then presented. The forecasts, on a quarterly basis or annual representing sums of monthly levels, are reported simply for the sake of brevity. The forecasts are made from the time origin of December 1976.

The forecasts of economic activity come from the Data Resources, Incorporated Trend (9/76) simulation, while the forecasts of the price data are interpolated from the base case forecasts in the 1976 National Energy Outlook [3]. In 1977 actual weather variation is used in reporting the forecast results. That is, the forecasts are adjusted for actual weather. Normal weather is anticipated in the 1978 and 1979 forecasts.

The forecasts of actual generation and coal consumption are given in Table 6a - Table 6c on a monthly basis. The model performs remarkably well in all instances except for coal consumption in the New England Region. The poor performance there is not surprising in light of the fact that only one state, New Hampshire, burned any appreciable amount of coal and that was relatively small. Oil and natural gas are the preferred boiler fuels and when they are not available or are in short supply, coal is used. The structural relationship, relating coal consumption to generation, however, is not strong enough so that on average over the twelvemonth period a 3.02 percent error is made in the forecasts.

For all forecasts besides that for coal in New England, the forecast error is consistently under 5 percent. This value of 5 percent is what electric utilities use as the line of demarcation between acceptable and unacceptable forecasting accuracy (Galiana [4]).

What do the forecasts portend for the future? Other things being equal, electrical energy generation will grow between 1976 and 1979 at a rate of 3.65 percent, 3.91 percent, and 3.41 percent in New England, New York, and the PJM regions, respectively. This is less than the historical average for the regions (the average being in the range of 6 to 7 percent over the period 1950 through 1970). It is consistent with the increased awareness of conservation efforts, the relatively mild forecast of the growth in economic activity and the expected continued rise in the real price of electrical energy. Additionally, the economic future is not as bright for these regions as it is for the United States in the aggregate (Meyer and Leone [6]).

With regard to coal consumption by electric utilities, coal is forecast to become increasingly important as a boiler fuel relative to other fuels. Thus, coal consumption in the New York and PJM regions should increase 
TABLE 6A

Actual and Forecast Generation and Coal Consumption for 1977-New England

\begin{tabular}{|c|c|c|c|c|c|c|c|c|c|c|c|c|c|}
\hline & Jan. & Feb. & Mar. & Apr. & May & June & July & Aug. & Sept. & Oct. & Nov. & $\underline{\text { Dec. }}$ & TOTAL \\
\hline \multicolumn{14}{|l|}{ 1. Generation ${ }^{1}$} \\
\hline a. Actual & 7646 & 6539 & 6497 & 6105 & 5597 & 5798 & 6325 & 6427 & 5836 & 5995 & 6191 & 7094 & 76,050 \\
\hline b. Forecast & 7511 & 6437 & 6329 & 6090 & 5633 & 5641 & 5099 & 6380 & 5969 & 6002 & 6332 & 7243 & 75,666 \\
\hline c. $\%$ error $^{2}$ & 1.77 & 1.56 & 2.59 & 0.25 & 0.64 & 2.71 & 3.57 & 0.73 & 2.28 & 0.12 & 2.28 & 2.10 & 0.50 \\
\hline \multicolumn{14}{|c|}{$\begin{array}{l}\text { 2. Coal } \\
\text { Consumption }^{3}\end{array}$} \\
\hline a. Actual & 111 & 88 & 78 & 63 & 100 & 55 & 33 & 86 & 66 & 86 & 93 & 102 & 961 \\
\hline b. Forecast & 106 & 93 & 81 & 70 & 68 & 60 & 38 & 69 & 71 & 84 & 92 & 100 & 932 \\
\hline c. $\%$ error $^{2}$ & 4.50 & 5.68 & 3.85 & 10.00 & 32.00 & 9.10 & 15.15 & 19.77 & 7.58 & 2.33 & 1.08 & 1.96 & 3.02 \\
\hline \multicolumn{14}{|c|}{$\begin{array}{l}\text { 'In gigawatt-hours. } \\
\text { ' }(\mid \text { Actual一Forecast } \mid / \text { Actual }) * 100 . \\
\text { In thousands of tons. }\end{array}$} \\
\hline
\end{tabular}




\section{TABLE 6B}

Actual and Forecast Generation and Coal Consumption for 1977-New York

\begin{tabular}{|c|c|c|c|c|c|c|c|c|c|c|c|c|c|}
\hline & Jan. & Feb. & Mar. & Apr. & May & June & July & Aug. & Sept. & Oct. & Nov. & Dec. & TOTAL \\
\hline \multicolumn{14}{|l|}{ 1. Generation ${ }^{1}$} \\
\hline a. Actual & 10,664 & 8861 & 9713 & 8496 & 9012 & 9082 & 9459 & 10,178 & 9130 & 8935 & 9243 & 9,898 & 112,671 \\
\hline b. Forecast & 10,898 & 9062 & 9610 & 8514 & 8917 & 9149 & 9678 & 10,138 & 9200 & 9033 & 9277 & 10,025 & 113,501 \\
\hline c. $\%$ error $^{2}$ & 2.19 & 2.26 & 1.06 & 0.21 & 1.05 & 0.73 & 2.32 & 0.39 & 0.77 & 1.10 & 0.37 & 1.28 & 0.74 \\
\hline $\begin{array}{l}\text { 2. Coal } \\
\text { Consumption }\end{array}$ & & & & & & & & & & & & & \\
\hline a. Actual & 569 & 510 & 570 & 576 & 587 & 521 & 576 & 592 & 496 & 503 & 544 & 574 & 6618 \\
\hline b. Forecast & 581 & 531 & 568 & 571 & 573 & 539 & 598 & 604 & 512 & 518 & 564 & 583 & 6742 \\
\hline c. $\%$ error $^{2}$ & 2.11 & 4.11 & 0.35 & 0.87 & 2.39 & 3.45 & 3.82 & 2.03 & 3.23 & 2.98 & 3.68 & 1.57 & 1.87 \\
\hline
\end{tabular}

1, 2. 3 See Table 6a for description. 
TABLE 6C

Actual and Forecast Generation and Coal Consumption for 1977-PJM

\begin{tabular}{|c|c|c|c|c|c|c|c|c|c|c|c|c|c|}
\hline & Jan. & Feb. & March & April & May & June & July & Aug. & Sept. & Oct. & Nov. & Dec. & TOTAL \\
\hline \multicolumn{14}{|l|}{ 1. Generation ${ }^{1}$} \\
\hline a. Actual & 16,691 & 13,637 & 13,846 & 13,115 & 14,597 & 14,564 & 16,438 & 17,188 & 14,570 & 14,210 & 14,934 & 15,217 & 179,007 \\
\hline b. Forecast & 16,466 & 14,002 & 13,991 & 13,402 & 14,040 & 14,028 & 15,993 & 16,984 & 14,631 & 13,972 & 14,502 & 14,898 & 176,909 \\
\hline c. $\%$ error $^{2}$ & 1.35 & 2.68 & 1.05 & 2.19 & 3.82 & 3.68 & 2.71 & 1.19 & 0.42 & 1.67 & 2.89 & 2.10 & 1.17 \\
\hline \multicolumn{14}{|c|}{$\begin{array}{l}\text { 2. Coal } \\
\text { Consumption }\end{array}$} \\
\hline a. Actual & 3,797 & 3,416 & 3,256 & 3,085 & 3,534 & 3,713 & 3,890 & 3,932 & 3,800 & 3,591 & 3,602 & 3,699 & 43,315 \\
\hline b. Forecast & 3,663 & 3,505 & 3,300 & 2,988 & 3,437 & 3,619 & 3,783 & 3,892 & 3,754 & 3,525 & 3,629 & 3,752 & 42,841 \\
\hline c. $\%$ error $^{2}$ & 3.53 & 2.61 & 1.35 & 3.14 & 2.74 & 2.53 & 2.75 & 1.02 & 1.21 & 1.84 & 0.75 & 1.43 & 1.08 \\
\hline
\end{tabular}

1, 2, 3ee Table 6a for description. 
TABLE 7A

Forecast Generation and Coal Consumption for 1978 and 1978-New England

\begin{tabular}{|c|c|c|c|c|c|c|c|}
\hline \multirow[b]{2}{*}{ 1. Generation } & \multicolumn{5}{|c|}{1978} & \multirow[b]{2}{*}{1979} & \multirow{2}{*}{$\begin{array}{c}\text { Annual Growth Rate } \\
1976-1979 \\
\text { (in percent) }\end{array}$} \\
\hline & $\mathrm{Q}^{1}$ & $\mathrm{Q}_{2}$ & $\mathrm{Q}_{3}$ & $\mathrm{Q}_{4}$ & TOTAL & & \\
\hline a. Forecast & 20,232 & 19,173 & 21,258 & 20,279 & 80,942 & 84,467 & 3.65 \\
\hline b. Confidence Interval ${ }^{2}$ & 1,077 & 1,077 & 1,077 & 1,077 & 4,308 & 4,680 & \\
\hline \multicolumn{8}{|l|}{ 2. Coal Consumption } \\
\hline a. Forecast & 275 & 266 & 284 & 276 & 1,101 & 1,204 & 16.00 \\
\hline b. Confidence Interval & 15 & 15 & 15 & 15 & 60 & 66 & \\
\hline
\end{tabular}

${ }^{1} Q_{1}$ denotes quarter 1 , and so forth.

${ }^{2} 95$ percent confidence interval; that is, the probability that the true value lies between the forecast period plus confidence interval and forecast period minus confidence interval is 95 percent. 


\section{TABLE 7B}

Forecast Generation and Coal Consumption for 1978 and 1978-New York

\begin{tabular}{|c|c|c|c|c|c|c|c|}
\hline \multirow{2}{*}{ 1. Generation } & \multicolumn{5}{|c|}{1978} & \multirow[b]{2}{*}{1979} & \multirow{2}{*}{$\begin{array}{c}\text { Annual Growth Rate } \\
1976-1979 \\
\text { (in percent) }\end{array}$} \\
\hline & $\mathrm{Q}_{1}{ }^{1}$ & $\mathrm{Q}_{2}$ & $\mathrm{Q}_{3}$ & $\mathrm{Q}_{4}$ & TOTAL & & \\
\hline a. Forecast & 29,830 & 28,269 & 31,345 & 39,898 & 119,342 & 122,226 & 3.91 \\
\hline b. Confidence Interval ${ }^{2}$ & 1,590 & 1,590 & 1,590 & 1,590 & 6,360 & 6,804 & \\
\hline \multicolumn{8}{|l|}{ 2. Coal Consumption } \\
\hline a. Forecast & 1,678 & 1,591 & 1,764 & 1,682 & 6,715 & 6,802 & 4.17 \\
\hline b. Confidence Interval & 89 & 89 & 89 & 89 & 356 & 378 & \\
\hline
\end{tabular}

1. 2See Table 7a for description. 
TABLE 7C:

Forecast Generation and Coal Consumption for 1978 and 1979-PJM

\begin{tabular}{|c|c|c|c|c|c|c|c|}
\hline \multirow[b]{2}{*}{ 1. Generation } & \multicolumn{5}{|c|}{1978} & \multirow[b]{2}{*}{1979} & \multirow{2}{*}{$\begin{array}{c}\text { Annual (rowth Rate } \\
1976-1979 \\
\text { (in percent) }\end{array}$} \\
\hline & $Q_{1}{ }^{1}$ & $Q$ & $Q_{3}$ & $Q_{+}$ & TOTAL & & \\
\hline a. Forecast & $4 \overline{6,175}$ & $4 \overline{3,759}$ & $48 \overline{5} 19$ & $4 \overline{6,280}$ & $\overline{184,733}$ & $1 \overline{89,601}$ & 3.41 \\
\hline b. Confidence Interval ${ }^{2}$ & 2,460 & 2,460 & 2,460 & 2,460 & 9,840 & 10,572 & \\
\hline \multicolumn{8}{|l|}{ 2. Coal Consumption } \\
\hline a. Forecast & 12,387 & 11,739 & 13,017 & 12,416 & 49,559 & 51,545 & 4.53 \\
\hline b. Confidence Interval & 660 & 660 & 660 & 660 & 2,640 & 2,874 & \\
\hline
\end{tabular}

1. 2See Table 7a for description. 
between 1976 and 1979 at an annual rate of 4.17 percent and 4.53 percent, respectively. Further (keeping in mind the poor forecasting performances for coal in the region), coal is likely to become much more significant than it has been in the recent past. Since oil has become very expensive relative to coal and natural gas deliveries, at least during the heating season, are being curtailed to electric utilities the only viable short-run alternative is coal. Historically, coal has been a significant fuel for the generation of electrical energy in New England, ${ }^{13}$ and the forecast simply indicates that, even with the more stringent environmental safeguards, coal consumption will move toward a position of greater importance in the generation of electrical energy.

\section{CONCLUSION}

In the foregoing pages a model combining the strengths of an econometric approach and the strengths of a Box-Jenkins time series approach has been developed to provide short-run regional forecasts for electrical energy generation and electric utility coal consumption. For the North East Region in general, the predictive performance of the model is excellent. Further, through at least 1979, increases in generation will be somewhat less than what has historically been true and coal will increase slightly in importance as a boiler fuel for electrical energy generation.

\section{FOOTNOTES}

'For example, Taylor [9], [10].

${ }^{2}$ Halvorsen [5], for the residential sector, for example, confirms the efficacy of an econometric approach. Uri [14], for all sectors, shows that an econometric approach provides very satisfactory results.

${ }^{3}$ This is accomplished by weighing each sector's contribution to the price by its proportion of total generation.

${ }^{4}$ The New England Region consists of Connecticut, Maine, Massachusetts, New Hampshire, Rhode Island, and Vermont.

${ }^{5}$ See Suits [15] for a discussion on how this is done.

${ }^{6}$ An estimate of the Durbin-Watson statistic is not reported because of its well-known deficiencies with a lagged endogenous variable (Nerlove and Wallis [8]).

${ }^{7} \mathrm{~A}$ load duration curve is a plot of the load demanded on a system in decreasing order of magnitude over the period of interest.

${ }^{8}$ Box and Jenkins [2]

${ }^{9}$ Witness the usual non-inclusion of a weather variable in econometric models of the demand for electrical energy.

${ }^{10}$ This section draws upon the paper by Uri [13].

${ }^{11}$ Other variables were considered in preliminary analyses proved to be uniformly insignificant.

${ }^{12} \mathrm{~A}$ degree day is a unit measuring the extent to which the outdoor mean (average of maximum and minimum) daily dry-bulb temperature falls below (in the case of heating) or rises above (in the case of cooling) a base of 65 degrees Fahrenheit.

${ }^{13}$ In 1965,55 percent of the fossil fuel burned in electric utility boilers was coal.

\section{REFERENCES}

| 1. Ames, E., and S. Reiter, "Distribution of Correlation Coefficients in Economic Time Series, ${ }^{n}$ Journal of the American Statistical Association, Vol. 56, no. 295 (September 1961), pp. 637-656.

2. Box, G.E.P. and G.M. Jenkins, Time Series Analysis, Forecasting and Control, Holden-Day, San Francisco, 1970.

3. Federal Energy Administration, 1976 National Energy Outlook, U.S. Government Printing Office, Washington, D.C., 1977.

4. Galiana, F., "Short-Term Forecasting," Proceedings of a Workshop on Forecasting Methodology for Time-of-Day and Seasonal Electric Utility Loads, (J. Boyd, ed.), Electric Power Research Institute, Palo Alto, 1975.

5. Halvorsen, R., "Residential Demand for Electric Energy," The Review of Economics and Statistics, Vol. LVII (February 1975), pp. 12-18.
6. Meyer, J.R. and R.A. Leone, "The New England States and Their Economic Future," processed, December 1977.

7. Nelson, C.R., "The First-Order Moving Average Process," Journal of Econometrics, Vol. 2, No. 2 (July 1974), pp. 121-137.

8. Nerlove, M. and K.F. Wallis, "Use of the DurbinWatson Statistic in Inappropriate Situations," Econometrica, Vol. 34 (1966), pp. 235-238.

9. Taylor, L., "The Demand for Electricity: A Survey," The Bell Jounral of Economics, Vol. 6 (Spring 1975), pp. 74-110.

10. , "The Demand for Energy: A Survey of Price and Income Elasticities," processed, April 1976.

11. Thompson, H.E., and G.C. Tiao, "Analysis of Telephone Data: A Case Study of Forecasting Seasonal 
Time Series," The Bell Journal of Economics and Management Science, Vol. 2, No. 21 (Autumn 1971), pp. 515-541.

12. Uri, N.D., "Regional Inter-fuel Substitution by Electric Utilities in the United States," Journal of Regional Science, Vol. 17, No. 2 (August 1977), pp. 212-226.

13. "Quantifying the Regional Impact of Weather Variations on Electrical Energy Genera- tion," The Review of Regional Studies, forthcoming.

14. , "The Demand for Electrical Energy in the United States," Energy Systems and Policy, forthcoming.

15. Suits, D.B., "Use of Dummy Variables in Regression Equations," The Journal of the American Statistical Association, Vol. 52, (December 1957), pp. 548-551. 